\title{
Cladribine to Treat Relapsing Forms of Multiple Sclerosis
}

\author{
Gavin Giovannoni ${ }^{1}$ (iD
}

Published online: 22 November 2017

(C) The American Society for Experimental NeuroTherapeutics, Inc. 2017

\begin{abstract}
Cladribine is a purine nucleoside analogue that selectively depletes peripheral lymphocytes without a major impact on cells of the innate immune system. An oral formulation of cladribine has been developed to be given as short courses over two annual cycles. Oral cladribine results in the peripheral depletion of lymphocytes that is gradual, occurring over several weeks, and is not associated with a cell lysis syndrome, has a greater impact on B cells than $\mathrm{T}$ cells, and is followed by gradual reconstitution of the peripheral lymphocyte counts over several months. Oral cladribine is effective in relapsing forms of multiple sclerosis. As a selective immune reconstitution therapy (SIRT), cladribine acts as a short-term immunosuppressant, relative to other maintenance immunosuppressive therapies that result in long-term immunosuppression. The main safety signal that has emerge relates primarily to herpes zoster infection, which was more common in patients with higher grades of lymphopenia, in particular grade 3 and 4 lymphopenia. Data from the oral cladribine extension trial and safety register, and reanalysis of the pivotal phase III trial has indicated that oral cladribine is unlikely to be associated with an increased short- to intermediate-term risk of malignancy.
\end{abstract}

Keywords Oral cladribine $\cdot$ Multiple sclerosis $\cdot$ Selective immune reconstitution therapy

Gavin Giovannoni

g.giovannoni@qmul.ac.uk

1 Blizard Institute, Barts and The London School of Medicine and Dentistry, Queen Mary University London, London, UK

\section{Introduction}

Multiple sclerosis (MS) is a chronic inflammatory autoimmune disorder of the central nervous system (CNS) characterized by inflammation, demyelination, and variable degrees of axonal loss and gliosis. Inflammation is considered to be a pivotal component of MS pathology and involves both $\mathrm{T}$ and B cells and their products. Targeted reduction of lymphocyte subtypes is a successful therapeutic approach. Cladribine is a synthetic small molecule that depletes lymphocytes, which acts both in the periphery and possibly within the CNS [1-3].

Cladribine, a synthetic purine nucleoside analog, is a prodrug, that is resistant to deamination by the enzyme adenosine deaminase, but which undergoes intracellular phosphorylation by deoxycytidine kinase (DCK). Its active metabolite, cladribine triphosphate, accumulates within the cell, resulting in disruption of cellular metabolism, DNA damage and subsequent apoptosis $[4,5]$. Cladribine preferentially targets lymphocytes owing to their relatively high ratio of DCK to 5'nucleotidase, producing rapid and sustained reductions in $\mathrm{CD}^{+}$and $\mathrm{CD} 8^{+}$cells and rapid, though more transient, effects on $\mathrm{CD} 19^{+} \mathrm{B}$ cells. Cladribine is relatively sparing of other immune cells $[4,5]$. Cladribine was developed as a result of the understanding of the molecular basis of the genetic disease adenosine deaminase (ADA) deficiency. In this condition, children experience severe immunodeficiency resulting from accumulation of toxic deoxyadenosine nucleotides in lymphocytes $[2,4]$. The effects of cladribine mimic the intracellular process that occurs in ADA deficiency. Parenteral cladribine is licensed for the treatment of active hairy-cell leukemia; extensive clinical experience with cladribine in oncology has been accumulated over $>3$ decades. 
Cladribine's mechanism of action provided the rationale to develop cladribine tablets as a potential agent for the treatment of MS. In clinical trials, cladribine has been found to be active in patients with relapsing-remitting forms of MS (RRMS) [3, $6,7]$. Reductions in lymphocyte counts are accompanied by reductions in proinflammatory cytokines, serum, and cerebrospinal fluid chemokine levels, adhesion molecule expression, and mononuclear cell migration [8-11].

Following the encouraging results with short treatment courses of parenteral cladribine in patients with $\mathrm{MS}[3,6,7]$, an oral tablet formulation was developed. The efficacy and safety of cladribine tablets were investigated in a 96-week, phase III, double-blind, placebo-controlled, multicenter pivotal trial in patients with RRMS: the CLARITY (CLAdRIbine tablets Treating multiple sclerosis orallY) study (clinicaltrials.gov identifier: NCT00213135, EudraCT number: 2004-005148-28) [12]. Cladribine tablets differ from currently available MS treatments because they are given as short-course orally, requiring only 8 to 10 days of treatment per 48 -week cycle.

This article will review the mechanism of action of cladribine tablets, summarize data from clinical trials in patients with MS, and provide guidance on the management of these patients in clinical practice.

\section{Mechanism of Action}

The cladribine molecule (also referred to as $2-\mathrm{CdA}$ ) is an adenosine analogue, which enters cells via specific nucleoside transporter proteins. Cladribine acts as a prodrug, and its activity is dependent on the intracellular accumulation of its active triphosphate, which occurs preferentially in certain cell types [13]. Three intracellular enzymes play a key role in determining the availability of its active form (Fig. 1), 2-CdATP: 1) DCK (catalyzes the first of the 3 phosphorylation steps required to convert cladribine into its biologically active nucleotide triphosphate, 2-CdATP; 2) 5'-nucleotidase (5'-NTase) (catalyzes the reconversion of phosphorylated cladribine to the cladribine nucleoside; 3) ADA (in addition to dephosphorylation by 5'NTase, deamination by ADA can also remove phosphorylated nucleotides via deamination by ADA; however, cladribine is resistant to deamination by ADA owing to the substitution of a hydrogen atom by a chlorine atom).

The accumulation of the active 2-CdATP compound is dependent on the ratio of DCK, which creates it, to 5'NTases, which break it down [13]. This ratio varies between different cell types. Data from mRNA profiling studies in the public domain (BioGPS Database) [14] show that levels of DCK and the ratio of DCK:5'-NTases are high in T cells $\left(\mathrm{CD}^{+}, \mathrm{CD}^{+}\right), \mathrm{B}$ cells, and dendritic cells. In contrast, ratios are very low in numerous nonhematological cell types, including liver, heart, skin, brain, lung, kidney, ovarian, testicular, and germ cells. This results in selective accumulation of
CdATP in lymphocytes, allowing cladribine to preferentially target these cells [15]. As the active compound 2-CdATP builds up within lymphocytes, it results in inhibition of DNA synthesis and repair, disruption of cellular proliferation in actively dividing lymphocytes, and apoptosis and/or autophagy of quiescent lymphocytes through the accumulation of DNA strand breaks [15-18]. Alteration of cytokine patterns and induction of T-helper T-related cytokines may also contribute to the sustained effects of cladribine tablets seen in clinical trials [19].

\section{Early Studies}

Cladribine has been used extensively in a variety of hematological disorders $[20,21]$. Parenteral cladribine is used as a treatment for hairy cell leukemia [15]. Cladribine has been investigated in several other autoimmune disorders, including rheumatoid arthritis and systemic lupus erythematosusassociated glomerulonephritis [6, 22, 23]. Parenteral cladribine has been evaluated in both relapsing and progressive forms of MS. Three randomized, double-blind, parallelgroup, placebo-controlled, phase II/III trials have been conducted at the Scripps Research Institute (Scripps-C, MSScripps, and MS-001) [5, 7, 24]. In the placebo-controlled phases of these studies, 183 patients received intravenous or subcutaneous cladribine, at doses of 0.7 to $2.8 \mathrm{mg} / \mathrm{kg}$, administered in monthly 5 to 7-day courses for 2 to 6 months, and were followed for up to 24 months [24]. In all studies, parenteral cladribine was associated with a statistically significant improvement in magnetic resonance imaging (MRI) measures of disease activity regardless of dosing regimen or route of administration [24]. In the 18-month Scripps-C study, patients with RRMS received cladribine, $2.1 \mathrm{mg} / \mathrm{kg}$ subcutaneously, or placebo, and were followed for a further 12 months [7]. Treatment with parenteral cladribine led to a significant reduction in the number of gadolinium (Gd)-enhancing lesions at 12 months compared with placebo $(p=0.0001)$, which remained significantly lower at 18 months $(p=0.002)$ [7]. There was a significant reduction in a combined measure of the frequency and severity of relapses in patients receiving cladribine compared with those receiving placebo from months 7 to $12(p=$ 0.021), which was maintained at month $18(p=0.010)$ [7] Patients with progressive forms of MS received parenteral cladribine in the 12- month MS-001 and 24-month treatment crossover MS-Scripps studies [5, 24]. In MS-001, cladribine $(0.7$ or $2.1 \mathrm{mg} / \mathrm{kg}$ ) reduced the number and volume of T1 Gdenhancing lesions $(p<0.003)$ [5]. Prior to treatment crossover in the MS-Scripps study (after 12 months), significantly fewer patients receiving cladribine $(2.8 \mathrm{mg} / \mathrm{kg})$ than placebo had Gd-enhancing lesions: 2 of 24 patients receiving cladribine and 12 of 24 receiving placebo had Gd-enhancing lesions ( $p$ $<0.001$ ) [24]. Furthermore, disability and neurological 
Fig. 1 The accumulation of active cladribine (2-CdATP) is dependent on the ratio of deoxycytidine kinase (DCK), which creates it, to 5'nucleotidase (5'-NTases), which break it down [13]. This ratio varies between different cell types. Data from mRNA profiling studies in the public domain (BioGPS Database) [14] show that levels of DCK and the ratio of DCK:5'-NTases are high in T cells $\left(\mathrm{CD}^{+}, \mathrm{CD} 8^{+}\right), \mathrm{B}$ cells, and dendritic cells compared with non-hematological cell types, including liver, heart, skin, brain, lung, kidney, ovarian, testicular, and germ cells. This results in selective accumulation of CdATP in lymphocytes, allowing cladribine to preferentially target these cells [15].

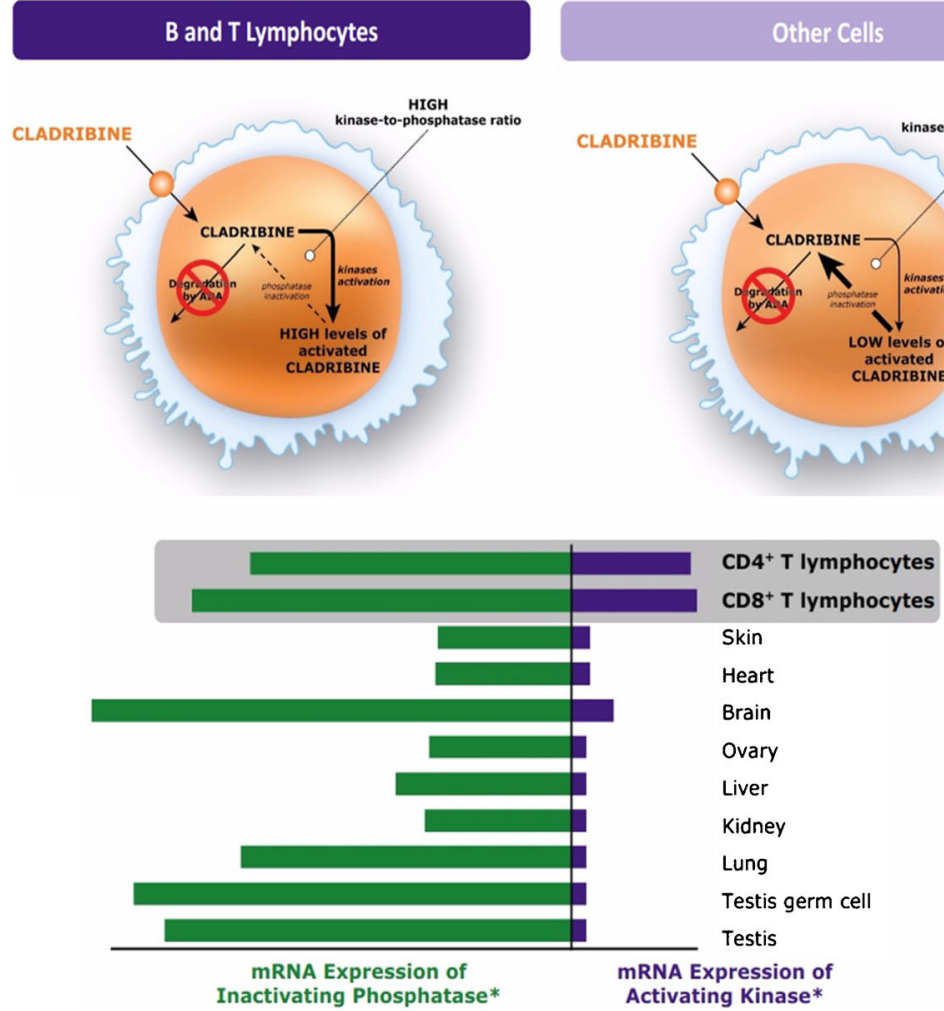

performance scores were significantly better in patients receiving cladribine than in those receiving placebo $(p<0.01$ and $p<0.001$, respectively) [24]. These latter results are difficult to interpret as patients with both secondary and primary progressive MS were included.

\section{Pharmacokinetics and Pharmacodynamics}

These parenteral studies showed encouraging results, which led to the development of an oral tablet form of cladribine. Oral cladribine is rapidly absorbed with a $\mathrm{C}_{\max }$ that is reached within 30-50 min of oral administration [25]. Oral bioavailability is between $37 \%$ and $51 \%$ and food intake does not significantly affect absorption of cladribine $[25,26]$. Up to $20 \%$ of cladribine is plasma protein bound [25]. The metabolism is not extensive; after oral administration $25 \pm 21 \%$ of a dose is excreted unchanged in urine and $3.8 \pm 1.9 \%$ as a metabolite [27]. Importantly in the context of MS cladribine is able to cross the blood-brain barrier, reaching a concentration in the cerebrospinal fluid of approximately $25 \%$ of that in the periphery. This should allow lymphocyte levels to be reduced at sites of focal inflammation in the brain, as well as in the periphery [28]. Cladribine has preferential and sustained activity in lymphocytes, reducing the circulating populations most notably for $\mathrm{CD} 4^{+}$lymphocytes, $\mathrm{CD} 8^{+}$lymphocytes, and B lymphocytes, with effects sustained for $\geq 10$ months following the last dose of either parenteral cladribine $[5,24,29]$ or oral cladribine tablets [30], which is likely due to cladribine's effect on both resting and actively dividing lymphocytes, including quiescent progenitor cells $[1,31]$. This prolonged recovery of lymphocyte populations allows for infrequent dosing and underpins the strategy of using an annual short-course treatment schedule. Cladribine has comparatively mild, transient effects on innate immune cells such as neutrophils following parenteral administration [5], an effect that was observed in the subsequent clinical trial of cladribine tablets [30]. This should allow, at least theoretically, relative preservation of an immunocompetent state [32].

\section{The Phase III CLARITY Study}

A pivotal phase III trial (CLARITY) placebo-controlled study was completed of cladribine tablets as monotherapy in RRMS [12] (Tables 1 and 2). In this 96-week trial, cladribine tablet therapy was studied as an annual short-course oral therapy for RRMS. Patients were assigned 1:1:1 to receive a cumulative dose over the 96 -week study of either cladribine $3.5 \mathrm{mg} / \mathrm{kg}$, cladribine $5.25 \mathrm{mg} / \mathrm{kg}$, or placebo. Treatment was administered orally as short courses, where each course consisted of once-daily dosing for 4 to 5 days. Patients received 2 or 4 short courses at 28-day intervals at the start of each 48-week treatment period. Eligible patients had RRMS [33], with lesions consistent with MS confirmed in prestudy MRI scans according to the Fazekas criteria [34], at least 1 relapse within 12 
months of study entry, and an Expanded Disability Status Scale score between 0 and 5.5. The primary endpoint was the rate of relapses at 96 weeks. Secondary endpoints included proportion of patients who were relapse-free, time to sustained progression of disability, time to first relapse, proportion of patients receiving rescue therapy, MRI endpoints, and safety assessments. In total, 1326 patients were enrolled, 1184 completed the full 96 weeks of study, and 1165 completed treatment [12]. Demographics and baseline characteristics were generally well balanced between groups, although mean duration of disease was shorter in patients in the cladribine 3.5 $\mathrm{mg} / \mathrm{kg}$ group $(p<0.05$ for the overall comparison across treatment groups). Approximately $70 \%$ of patients had not received prior disease-modifying drugs (DMDs). Of 456, 433, and 437 patients randomized to 5.25 or $3.5 \mathrm{mg} / \mathrm{kg}$ cladribine tablets or placebo, respectively, $87 \%$ to $92 \%$ completed the 96-week study and $86 \%$ to $91 \%$ completed full-course treatment to week 52 . The respective rates of treatment compliance (i.e., the number of tablets taken relative to the number of tablets expected to be taken) were $99.7 \%, 99.9 \%$, and $99.8 \%$, and the median time in study was longer with cladribine 5.25 or $3.5 \mathrm{mg} / \mathrm{kg}$ than placebo at 41.2 and 43.0 versus 36.1 weeks, respectively.

\section{Clinical Efficacy}

The annualized relapse rates (ARR) at 96 weeks were significantly reduced in both cladribine tablets groups versus placebo $(0.14,0.15$, and 0.33 in the $3.5 \mathrm{mg} / \mathrm{kg}, 5.25 \mathrm{mg} / \mathrm{kg}$ and placebo groups, respectively, for relative reductions of $57.6 \%$ and $54.5 \%$ vs placebo, respectively; each $p<0.001$ ) [12] (Tables 1 and 3). Early benefit of treatment effect was seen, with significantly lower relapse rates in both cladribine arms versus placebo by 16 weeks. The advantage of cladribine tablets over placebo in reducing ARR was seen across a range of clinically important patient subgroups in post-hoc analyses, when patients were stratified by factors including age, sex, prior DMD use, and baseline disease severity [35]. A significantly higher percentage of patients remained relapse-free at 96 weeks in both cladribine tablets groups versus placebo [79.7\% and $78.9 \%$ of patients in the $3.5 \mathrm{mg} / \mathrm{kg}$ and $5.25 \mathrm{mg} /$ $\mathrm{kg}$ groups were relapse-free, respectively, vs $60.9 \%$ in the placebo group (each $p<0.001 v s$ placebo)] [12]. Time to first relapse was significantly longer in both the cladribine tablets groups compared with placebo (each $p<0.001$ ). In the placebo group, the fifteenth percentile of time to event was 4.6 months versus 13.4 months [hazard ratio (HR) 0.44] and 13.3 months (HR 0.46) in the $3.5 \mathrm{mg} / \mathrm{kg}$ and $5.25 \mathrm{mg} / \mathrm{kg}$ groups, respectively. Significantly more patients in the placebo group required rescue therapy compared with those receiving cladribine tablet treatment $[6.2 \%$ in the placebo group $v s$ $2.5 \%(p<0.001$ for the comparison) and $2.0 \%(p=0.003)$ in the cladribine $3.5 \mathrm{mg} / \mathrm{kg}$ and $5.25 \mathrm{mg} / \mathrm{kg}$ groups, respectively]. The time from last dose to rescue therapy was similar across groups, with a median of 178 (range -4 to 678) days for $5.25 \mathrm{mg} / \mathrm{kg}, 131$ (range $60-300$ ) days for $3.5 \mathrm{mg} / \mathrm{kg}$, and 163 (range 31-592) days for placebo. Time to 3-month sustained change in Expanded Disability Status Scale score was significantly longer in patients receiving cladribine tablets treatment [13.6 months in each cladribine arm vs 10.8 months with placebo; HR $0.67(p=0.02)$ in the $3.5 \mathrm{mg} / \mathrm{kg}$ group and HR $0.69(p=0.03)$ in the $5.25 \mathrm{mg} / \mathrm{kg}$ group]. The odds of remaining free of 3-month disability progression were increased in both the cladribine treatment groups versus placebo [odds ratio (OR) $1.55(p=0.02)$ and OR $1.46(p=0.03)$ in the $3.5 \mathrm{mg} / \mathrm{kg}$ and $5 / 25 \mathrm{mg} / \mathrm{kg}$ groups, respectively].

MRI analyses at 96 weeks showed relative reductions in T1 Gd-enhancing lesions with cladribine in the 3.5 and 5.25 $\mathrm{mg} / \mathrm{kg}$ groups of $85.7 \%$ and $87.9 \%$, respectively, versus placebo (both $p<0.001$ ) $[12,36]$. Relative reductions in active $\mathrm{T} 2$ lesions of $73.4 \%$ and $76.9 \%$ were observed with cladribine tablets therapy in the 3.5 and $5.25 \mathrm{mg} / \mathrm{kg}$ groups, respectively, versus placebo (both $p<0.001$ ). Relative reductions of $74.4 \%$ and $77.9 \%$ in combined unique lesions were observed with cladribine tablets therapy in the 3.5 and $5.25 \mathrm{mg} / \mathrm{kg}$ groups, respectively, versus placebo (both $p<$ 0.001). Significant improvements in MRI outcomes were consistently observed in clinically relevant patient subgroups stratified according to baseline disease severity [37]. When stratified by baseline relapse rate, the relative reductions in combined unique lesions/patient/scan for the 3.5 and $5.25 \mathrm{mg} / \mathrm{kg}$ groups were $74.8 \%$ and $75.5 \%(\leq 1$ relapse), $83.1 \%$ and $86.7 \%$ ( 2 relapses), and $76.7 \%$ and $90.0 \%$ ( $\geq 3$ relapses), respectively (all $p<0.001$ ). Similarly, relative reductions were $73.5 \%$ and $75.2 \%$ for patients without $\mathrm{T} 1 \mathrm{Gd}$-enhancing lesions at baseline, and $80.8 \%$ and $84.9 \%$ for patients with $\geq 1 \mathrm{~T} 1 \mathrm{Gd}$-enhancing lesion(s) at baseline, respectively (all $p<0.001$ ) [37].

Disease activity-free status, or NEDA (no evident disease activity), a composite measure of efficacy, was analyzed posthoc and confirmed the efficacy findings [38]. In the cladribine tablets 3.5 and $5.25 \mathrm{mg} / \mathrm{kg}$ versus placebo groups, respectively, $67.3 \%$ and $69.7 \%$ versus $38.9 \%$ of patients were disease activity-free over 24 weeks; $54.2 \%$ and $56.1 \%$ versus $23.9 \%$ over 48 weeks; and $44.2 \%$ and $46.0 \%$ versus $15.8 \%$ over the entire 96-week study (all $p<0.001$ for active treatments $v s$ placebo) [38]. Significant differences between cladribine tablets and placebo disease activity-free status were seen across patient subgroups, including patients who had received prior disease-modifying therapy $(37.2 \%$ and $42.9 \%$ for cladribine tablets 3.5 and $5.25 \mathrm{mg} / \mathrm{kg}$ vs $16.2 \%$ for placebo) and treatment-naïve patients $(45.0 \%$ and $45.0 \%$ vs $15.9 \%)$; patients with baseline disease duration $<3$ years $(38.1 \%$ and $46.5 \%$ vs $8.2 \%), 3$ to 10 years $(47.0 \%$ and $40.3 \%$ vs $15.5 \%)$, and $>10$ years $(41.8 \%$ and $47.8 \%$ vs $22.1 \%$ ) (all $p<0.001$ for active 
treatments vs placebo) [38]. ORs for patients remaining disease activity-free with cladribine tablets $3.5 \mathrm{mg} / \mathrm{kg}$ and 5.25 $\mathrm{mg} / \mathrm{kg}$ treatment versus placebo were 3.99 [95\% confidence interval (CI) 2.89-5.49] and 4.24 (95\% CI 3.09-5.82), respectively (each $p<0.001)$ [38].

In the CLARITY study, the effect of 2 years' treatment on annualized percentage brain volume change (PBVC/y) was evaluated. Compared with placebo $(-0.70 \% \pm 0.79), \mathrm{PBVC} / \mathrm{y}$ was reduced in patients treated with cladribine tablets $3.5 \mathrm{mg} /$ $\mathrm{kg}(-0.56 \% \pm 0.68 ; p=0.010)$ and $5.25 \mathrm{mg} / \mathrm{kg}(-0.57 \% \pm 0.72$; $p=0.019$ ) [39]. In this analysis, after adjusting for treatment group, PBVC/y showed a significant correlation with the cumulative probability of disability progression (HR $0.67,95 \%$ CI $0.571-0.787 ; p<0.001$ ), with patients with lower PBVC/y showing the highest probability of remaining free from disability progression at 2 years and vice versa [39].

\section{Considerations for Patient Management}

The efficacy and safety findings in the CLARITY study were associated with additional benefits in reducing healthcare resource utilization [41]. In a comparison of resource use across treatment arms, the outcomes observed during the CLARITY study were associated with a reduced consumption of healthcare resources and a decreased need for medical and societal support, suggesting a potential economic benefit of treatment with cladribine tablets [41]. Compared with placebo, the mean number of hospital days per patient over 96 weeks was 3.90 days and 1.92 days fewer in the cladribine tablets $3.5 \mathrm{mg} / \mathrm{kg}$ and $5.25 \mathrm{mg} / \mathrm{kg}$ groups, respectively (both $p$ $<0.01$ ) [41]. The number of emergency room visits, clinic visits, and missed work days was also significantly lower for both cladribine tablets treatment arms compared with placebo. Additionally, corticosteroid use was lower amongst patients in the cladribine tablets groups than in the placebo group (mainly owing to fewer relapses) [41].

\section{Comparing CLARITY with CLARITY Extension}

A post-hoc analysis evaluated the longitudinal effect of cladribine tablets by comparing key outcomes in treatment groups at the end of CLARITY Extension with the outcomes in the same patients at the end of CLARITY (i.e., comparing the same patients at different times). This showed that ARR and the proportion of relapse-free patients were broadly similar between CLARITY and CLARITY Extension (Fig. 2A, B). In patients randomized to placebo in CLARITY Extension, the benefits of treatment with cladribine tablets in CLARITY were largely maintained. As expected, patients randomized to placebo in CLARITY (for ethical reasons, these patients were allocated to cladribine tablets $3.5 \mathrm{mg} / \mathrm{kg}$ during CLARITY Extension) showed significant improvements in ARR and the proportion of relapse-free patients [42].

\section{Lymphocyte Counts During CLARITY and CLARITY Extension}

Immunosuppressive agents like cladribine have pronounced effects on immune function, and it is relevant to assess the effects of treatment on lymphocyte counts. Analysis of pooled data from patients treated with cladribine tablets $3.5 \mathrm{mg} / \mathrm{kg}$ in CLARITY and CLARITY Extension showed rapid reductions in absolute lymphocyte counts in the first and second years of active treatment, followed by a gradual return to the normal range towards the end of each treatment period with median lymphocyte counts within the normal range from the end of the second year of treatment onwards (Fig. 3) [43]. Considered in the context of the durable outcomes obtained in CLARITY Extension (Fig. 2), these findings indicate that the lasting efficacy of cladribine tablets occurs against a background of significant changes in lymphocyte counts and subpopulations [43] .

\section{ORACLE-MS}

The ORAl CLadribine for Early MS (ORACLE-MS) study assessed the use of cladribine tablets in patients with early disease (clinically isolated syndrome), who were at high risk of conversion to MS. ORACLE-MS was a 2-year (96-week) randomized, double-blind study in patients who had experienced a first demyelinating event [44] (Table 1). Although the ORACLE study was terminated early by the study sponsor, because of a negative regulatory decision in relation the CLARITY data, compared with placebo, cladribine 3.5 and $5.25 \mathrm{mg} / \mathrm{kg}$ significantly delayed conversion to clinically definite MS using Poser criteria (primary efficacy endpoint; $p<$ 0.0001 for each), and the $2005 \mathrm{McDonald}$ criteria (main secondary endpoint; $p<0.0001$ for each) [44].

\section{Safety and Tolerability}

Cladribine tablets have a safety and tolerability profile that has been established and shown to be consistent across several studies (Tables 4 and 5). In CLARITY and CLARITY Extension, approximately $90 \%$ of actively treated patients completed each study, and there were relatively few study discontinuations due to AEs $[12,45,46]$. Most AEs in each study were classed as mild or moderate, and most occurred at similar frequencies across treatment groups, with the exception of lymphopenia, which was higher in groups treated with cladribine tablets [45, 46]. The early termination of ORACLE-MS means that the rate of 


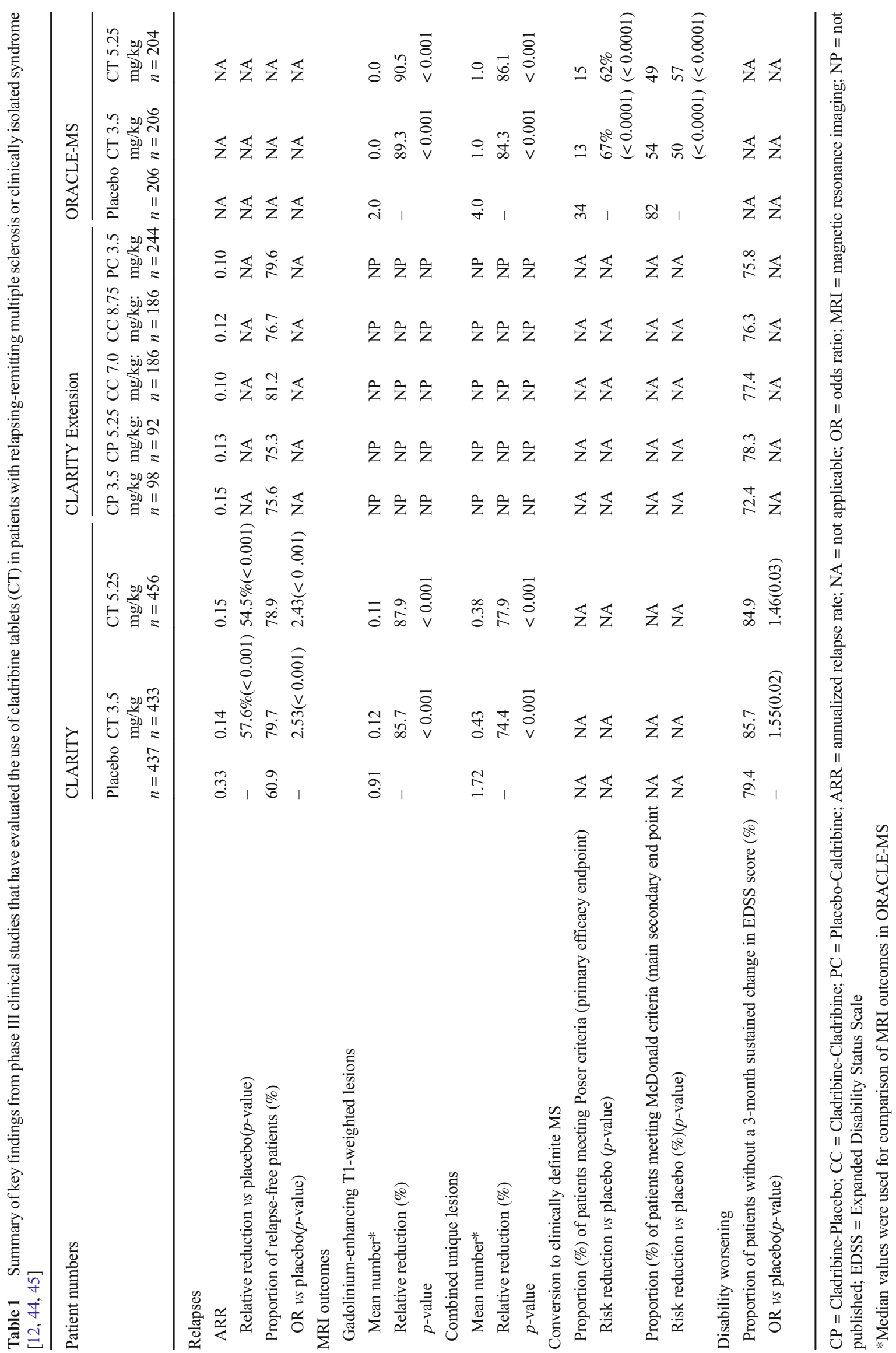


Fig. 2 Effects of treatment with cladribine (Clad) tablets or placebo (PBO) on (A) annualized relapse rates and (B) proportions of patients who remained relapse free [45]

$\mathrm{CP}=$ Cladribine-Placebo; $\mathrm{CC}=$ Cladribine-Cladribine; $\mathrm{PC}=$ Placebo-Caldribine

Fig. 3 Effects of treatment with cladribine tablets or placebo on median lymphocyte counts in CLARITY and CLARITY Extension [43] a

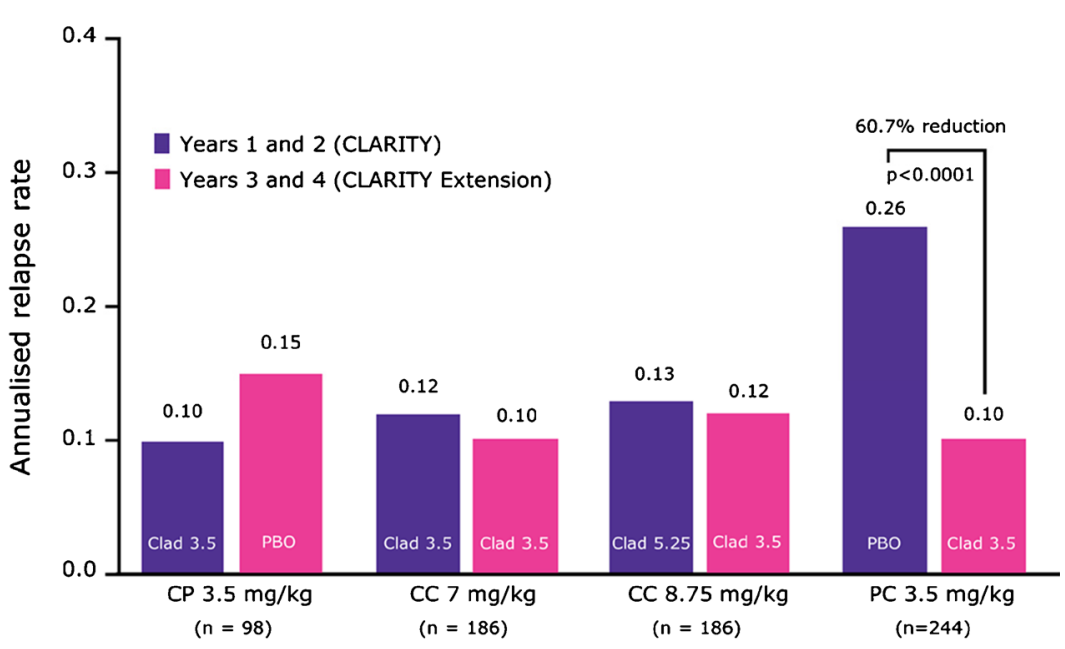

b

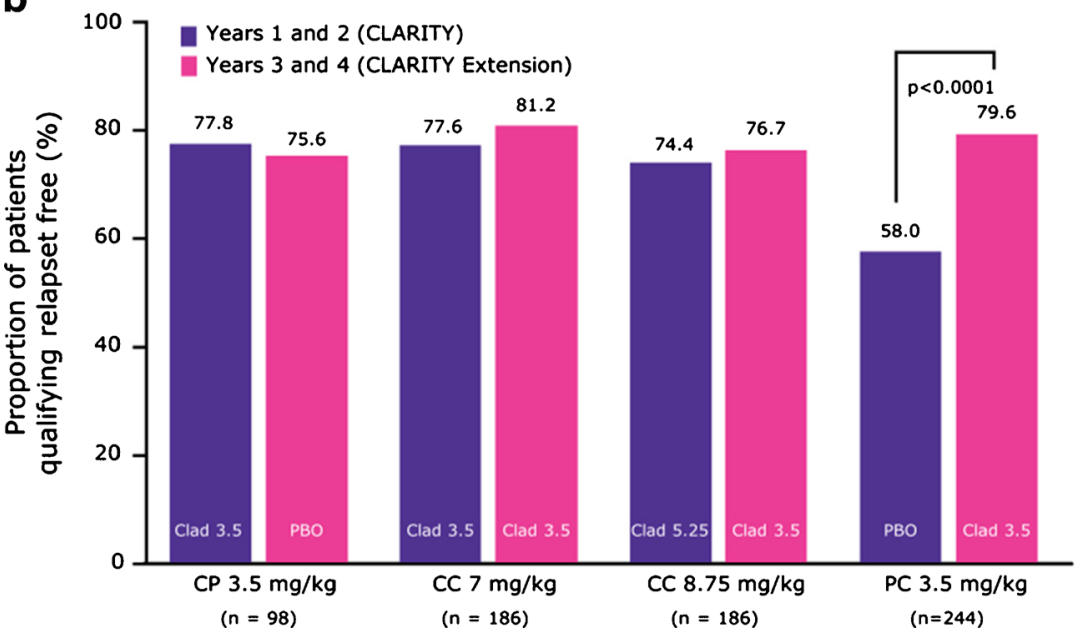

Clad, cladribine tablets; PBO, placebo; In A) and B) outcomes for treatment groups in CLARITY are shown in the lefthand column of each pair and outcomes for the same treatment groups in CLARITY Extension are shown in the righthand column. ${ }^{\dagger}$ qualifying relapses.

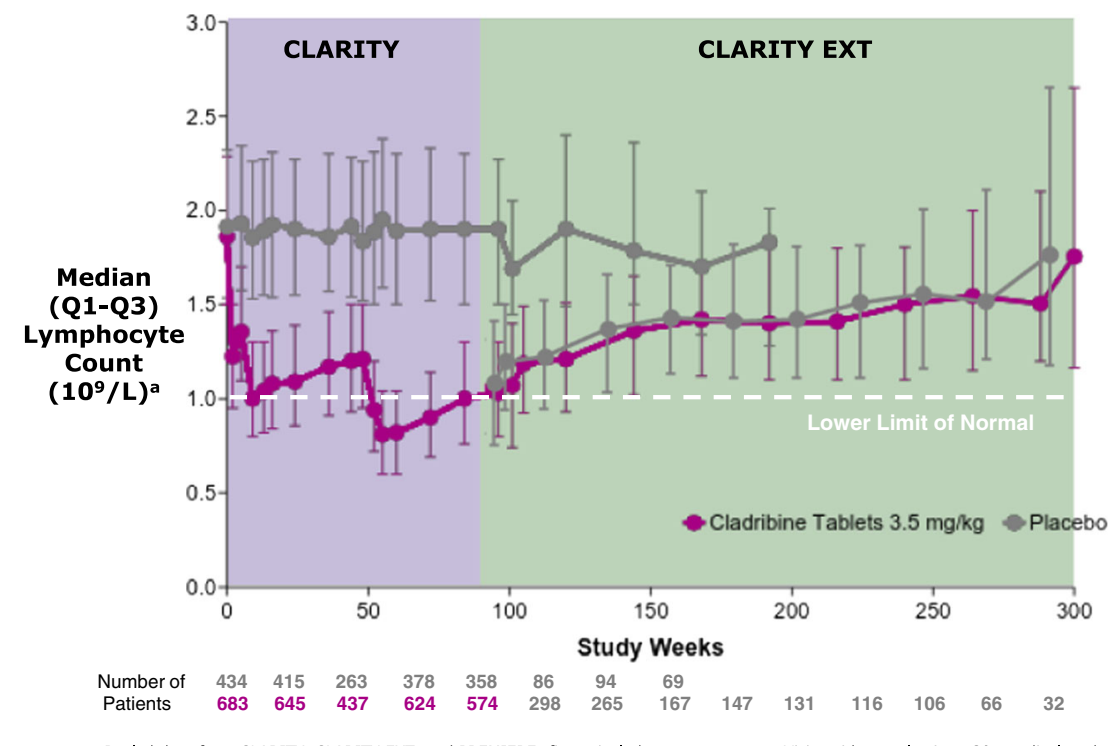

Pooled data from CLARITY, CLARITY EXT, and PREMIERE; figure includes treatment gap. Visits with sample size $\geq 30$ are displayed. 
discontinuations cannot be compared with CLARITY and CLARITY Extension. In general, the incidence and severity of AEs (most were classed as mild or moderate) in ORACLE-MS was comparable across treatment groups, except for lymphopenia, which was higher in groups treated with cladribine tablets.

\section{AEs of Special Interest}

\section{Lymphopenia}

Lymphopenia is an expected event based upon cladribine's mechanism of action, but efforts should be made to avoid severe, sustained lymphopenia. A retrospective analysis of CLARITY showed that severe lymphopenia could be avoided or reduced by using retreatment guidelines. Severe lymphopenia was not observed in patients who had a normal absolute lymphocyte count at CLARITY baseline and who recovered to Common Terminology Criteria for Adverse Events grade 0 or 1 lymphocyte counts before retreatment with cladribine tablets. The efficacy of cladribine tablets in terms of reducing ARR in these patients was comparable with the overall intent-to-treat population in CLARITY [47]. The benefits of this approach are illustrated in a year-by-year analysis of lymphopenia by Common Terminology Criteria for Adverse Events grade in CLARITY and CLARITY Extension. In patients who were treated with cladribine tablets $3.5 \mathrm{mg} / \mathrm{kg}$ in CLARITY and with cladribine tablets $3.5 \mathrm{mg} / \mathrm{kg}$ in CLARITY Extension according to retreatment guidelines, $>85 \%$ of patients had recovered to grade 0 or 1 lymphocyte counts and no patients had grade 4 lymphopenia at the end of each treatment year [43]. Treatment with cladribine tablets was associated with significant reductions in lymphocyte subtypes implicated in the pathogenesis of MS. The largest and most rapid reduction was in numbers of $\mathrm{CD} 19^{+}$ B lymphocytes, which showed a nadir approximately 13 weeks after dosing and recovery towards the normal range from 24 to 48 weeks after dosing $[43,48]$. Moderate, proportional reductions in T-lymphocyte counts occurred after treatment with cladribine tablets, with $\mathrm{CD} 8^{+}$cells showing a smaller decrease and faster recovery than $\mathrm{CD}^{+}$cells $[43,48]$. The clear dose effect in relation to T-lymphocyte depletion, but not $\mathrm{B}$ cells, suggests that cladribine's mode of action is more likely to be due to its effect on B cells. It should be noted that at the end of CLARITY, counts of $\mathrm{CD} 19^{+}$cells had recovered to within the normal range, and showed no sign of significant overshoot [48], a phenomenon observed with other immunosuppressant therapies like alemtuzumab [48].

\section{Infections}

In CLARITY and CLARITY Extension, incidence rates of the most common infections, including severe infections, were similar across groups, including patients treated with placebo.
The only exception to this was herpes zoster, which was more frequently observed in patients treated with cladribine tablets than with placebo $[12,45,46]$.

\section{Malignancies}

In CLARITY, the incidence of neoplasms (including benign, malignant, or unspecified) reported as a serious AE was slightly higher in patients treated with cladribine tablets 3.5 and $5.25 \mathrm{mg} / \mathrm{kg}$ (1.4\% and $0.9 \%$, respectively) than with placebo $(0.0 \%)$ [12]. In CLARITY Extension, the incidence of malignant or unspecified tumors population was $1.4 \%$ across all groups in the safety population. No clustering of malignancies with a common origin, and no hematological malignancies associated with immunosuppression was seen [12].

In ORACLE-MS, the incidence of neoplasms (benign, malignant, or unspecified) was lower in the cladribine tablets 3.5 and $5.25 \mathrm{mg} / \mathrm{kg}$ groups $(<1.0 \%$ and $1.0 \%$, respectively) than in the placebo group (3.0\%) [44]. Data from CLARITY and ORACLE-MS were included in an independent meta-analysis of malignancy rates in phase III clinical trials of DMDs in patients with RRMS. This found that the cancer rate was not increased versus treatment groups in other studies, and the risk difference for cladribine tablets versus placebo was not higher compared with DMDs in other studies [49]. The follow-up of 979 patients treated with cladribine for hairy cell leukemia, for a median of 5.1 years, reported an observed to expected frequency of secondary tumors of 1.50 (95\% CI 1.14-1.93), indicating a significant $(p<0.05)$ increase in risk for patients treated with cladribine compared with a normal population [50]. The 61 malignancies were most commonly lymphoma ( $n=13$ patients), prostate $(n=16)$, gastrointestinal $(n=6)$, breast $(n=5)$, bladder $(n=3)$, and lung $(n=3)$, and also CNS, stomach, ovary, melanoma, sarcoma, testicular, and myeloid leukemias [50]. However, these values are consistent with the increase already associated with hairy cell leukemia, which led to the conclusion that cladribine can be administered to patients with hairy cell leukemia without a significantly increased risk of secondary malignancies [50].

The apparent increased rate of malignancy in the CLARITY study and the fact that only one pivotal phase III study was initially submitted was the primary reason the European Medicine Agency did not approve oral cladribine in 2011. However, the analysis of the second phase III study (ORACLE), follow-on safety data from a safety register (PREMIERE study), epidemiological data indicating that there is no clear increased risk of secondary malignancy with cladribine, a modified dosing schedule to reduce the risk of persistent grade 3 and 4 lymphopenia, and a change in the regulatory environment led to a successful resubmission and licensing by the European Medicine Agency of oral cladribine for the treatment for relapsing MS in 2017. The latter explains 
why the oral cladribine development programme took so long to complete.

\section{Deaths}

There were 4 deaths during the study and 2 deaths after patients were withdrawn from study (withdrawals had been due to AEs); the 6 deaths were equally distributed across the 3 treatment groups [40]. Causes of death during the study were suicide (placebo), hemorrhagic stroke (placebo), acute myocardial infarction (cladribine $3.5 \mathrm{mg} / \mathrm{kg}$ ), and drowning (cladribine $5.25 \mathrm{mg} / \mathrm{kg}$ ) [40]. Causes of death following study withdrawal were metastatic pancreatic carcinoma (cladribine $3.5 \mathrm{mg} / \mathrm{kg}$ group) and acute cardiopulmonary arrest (cladribine $5.25 \mathrm{mg} / \mathrm{kg}$ ) [40]. The patient who died from metastatic pancreatic carcinoma was a 61-year-old woman in the $3.5 \mathrm{mg} / \mathrm{kg}$ group who was discontinued from the study following her week-72 visit due gastrointestinal and constitutional symptoms. She was subsequently diagnosed with metastatic pancreatic carcinoma and initiated chemotherapy but died about 3 months after diagnosis [40]. The acute cardiopulmonary arrest was considered to be related to an exacerbation of pre-existing tuberculosis. A 21-year-old woman in the $5.25 \mathrm{mg} / \mathrm{kg}$ group received a single treatment course of cladribine tablets $(0.875 \mathrm{mg} / \mathrm{kg})$; approximately 1 week after her last dose of cladribine she developed pancytopenia after which she was permanently withdrawn from treatment. A second episode of pancytopenia occurred approximately 2
Table 2 Baseline patient demographics and disease characteristics (intent-to-treat population) from the CLARITY study [12]

\begin{tabular}{|c|c|c|c|}
\hline & $\begin{array}{l}\text { Placebo } \\
(n=437)\end{array}$ & $\begin{array}{l}\text { Cladribine } \\
3.5 \mathrm{mg} / \mathrm{kg} \\
(\mathrm{n}=433)\end{array}$ & $\begin{array}{l}\text { Cladribine } \\
5.25 \mathrm{mg} / \mathrm{kg} \\
(\mathrm{n}=456)\end{array}$ \\
\hline \multicolumn{4}{|l|}{ Age (y) } \\
\hline Mean \pm SD & $38.7 \pm 9.9$ & $37.9 \pm 10.3$ & $39.1 \pm 9.9$ \\
\hline Range & $18-64$ & $18-65$ & $18-65$ \\
\hline Sex (female) & $288(65.9)$ & $298(68.8)$ & $312(68.4)$ \\
\hline Weight (mean \pm SD) (kg) & $70.3 \pm 15.4$ & $68.1 \pm 14.6$ & $69.3 \pm 14.8$ \\
\hline \multicolumn{4}{|l|}{ Ethnicity } \\
\hline White & $429(98.2)$ & $425(98.2)$ & $446(97.8)$ \\
\hline Black & $1(0.2)$ & $2(0.5)$ & $4(0.9)$ \\
\hline Other & $7(1.6)$ & $6(1.4)$ & $6(1.3)$ \\
\hline Prior treatment with any $\mathrm{DMD}^{*}$ & $142(32.5)$ & $113(26.1)$ & $147(32.2)$ \\
\hline \multicolumn{4}{|l|}{ Disease duration from first attack $(\mathrm{y})$} \\
\hline Mean \pm SD & $8.9 \pm 7.4$ & $7.9 \pm 7.2^{\dagger}$ & $9.3 \pm 7.6$ \\
\hline Range & $0.4-39.5$ & $0.3-42.3$ & $0.4-35.2$ \\
\hline \multicolumn{4}{|l|}{ EDSS category } \\
\hline 0 & $13(3.0)$ & $12(2.8)$ & $11(2.4)$ \\
\hline 1 & $70(16.0)$ & $75(17.3)$ & $80(17.5)$ \\
\hline 2 & $127(29.1)$ & $133(30.7)$ & $119(26.1)$ \\
\hline 3 & $96(22.0)$ & $108(24.9)$ & $108(23.7)$ \\
\hline 4 & $83(19.0)$ & $71(16.4)$ & $84(18.4)$ \\
\hline$\geq 5$ & $48(11.0)$ & $34(7.9)$ & $54(11.8)$ \\
\hline Mean \pm SD & $2.9 \pm 1.3$ & $2.8 \pm 1.2$ & $3.0 \pm 1.4$ \\
\hline \multicolumn{4}{|l|}{ T1 gadolinium-enhancing lesions } \\
\hline Patients with lesions & $128(29.3)$ & $138(31.9)$ & $147(32.2)$ \\
\hline Number of lesions (mean \pm SD) & $0.8 \pm 2.1$ & $1.0 \pm 2.7$ & $1.0 \pm 2.3$ \\
\hline \multicolumn{4}{|l|}{$\mathrm{T} 2$ lesion volume $\left(\mathrm{mm}^{3}\right)$} \\
\hline Mean \pm SD & $14287.6 \pm 13104.8$ & $14828.0 \pm 16266.8$ & $17202.1 \pm 17467.7$ \\
\hline
\end{tabular}

Data are $n(\%)$ unless otherwise indicated

DMD $=$ disease-modifying drug; EDSS $=$ Expanded Disability Status Scale

*Most commonly: intramuscular interferon (IFN)- $\beta 1$ a (Avonex, $11.2 \%$ ), subcutaneous IFN- $\beta 1$ a (Betaseron, $10.6 \%$ ), subcutaneous IFN- $\beta 1$ a (Rebif, 9.4\%), and subcutaneous glatiramer acetate (Copaxone, $6.5 \%$ )

${ }^{\dagger} p=0.005$ 
Table 3 Clinical and magnetic resonance imaging efficacy outcomes over 96 weeks (intent-to-treat population) from the CLARITY study [12]

\begin{tabular}{|c|c|c|c|}
\hline Endpoint & $\begin{array}{l}\text { Placebo } \\
(n=437)\end{array}$ & $\begin{array}{l}\text { Cladribine } \\
3.5 \mathrm{mg} / \mathrm{kg} \\
(\mathrm{n}=433)\end{array}$ & $\begin{array}{l}\text { Cladribine } \\
5.25 \mathrm{mg} / \mathrm{kg} \\
(\mathrm{n}=456)\end{array}$ \\
\hline \multicolumn{4}{|l|}{ Relapse rate — primary endpoint } \\
\hline $\operatorname{ARR}(95 \% \mathrm{CI})$ & $0.33(0.29-0.38)$ & $0.14(0.12-0.17)$ & $0.15(0.12-0.17)$ \\
\hline Relative reduction in ARR for cladribine $v s$ placebo $(\%)^{*}$ & & 57.6 & 54.5 \\
\hline$p$-value ${ }^{\dagger}$ & & $<0.001$ & $<0.001$ \\
\hline Relapse-free rate & $266(60.9)$ & $345(79.7)$ & $360(78.9)$ \\
\hline OR for cladribine $v s$ placebo, point estimate $(95 \% \mathrm{CI})^{\ddagger}$ & & $2.53(1.87-3.43)$ & $2.43(1.81-3.27)$ \\
\hline$p$-value ${ }^{\S}$ & & $<0.001$ & $<0.001$ \\
\hline \multicolumn{4}{|l|}{ Number of relapses over 96 weeks (patients) } \\
\hline 0 & $266(60.9)$ & $345(79.7)$ & $360(78.9)$ \\
\hline 1 & 109 (24.9) & $69(15.9)$ & $77(16.9)$ \\
\hline 2 & $44(10.1)$ & $13(3.0)$ & $13(2.9)$ \\
\hline 3 & $15(3.4)$ & $5(1.2)$ & $5(1.1)$ \\
\hline$\geq 4$ & $3(0.7)$ & $1(0.2)$ & $1(0.2)$ \\
\hline$p$-value $\mathrm{e}^{\mathrm{I}}$ & & $<0.001$ & $<0.001$ \\
\hline Patients receiving rescue therapy & $27(6.2)$ & $11(2.5)$ & $9(2.0)$ \\
\hline OR for cladribine $v s$ placebo, point estimate $(95 \% \mathrm{CI})^{\ddagger}$ & & $0.40(0.19-0.81)$ & $0.31(0.14-0.66)$ \\
\hline$p$-value ${ }^{\S}$ & & 0.01 & 0.003 \\
\hline Time to first relapse, 15 th percentile in days (months) ${ }^{\|}$ & $141(4.6)$ & $408(13.4)$ & $406(13.3)$ \\
\hline HR for cladribine $v s$ placebo, point estimate $(95 \% \mathrm{CI})^{* *}$ & & $0.44(0.34-0.58)$ & $0.46(0.36-0.60)$ \\
\hline$p$-value** & & $<0.001$ & $<0.001$ \\
\hline Time to 3-month sustained change in EDSS score, 10th percentile in days (months) $\|^{\|}$ & $330(10.8)$ & $414(13.6)$ & $414(13.6)$ \\
\hline HR for cladribine $v s$ placebo, point estimate $(95 \% \mathrm{CI}) * *$ & & $0.67(0.48-0.93)$ & $0.69(0.49-0.96)$ \\
\hline$p$-value ${ }^{* *}$ & & 0.02 & 0.03 \\
\hline Patients without a 3-month sustained change in EDSS score & $347(79.4)$ & $371(85.7)$ & $387(84.9)$ \\
\hline OR for cladribine $v s$ placebo, point estimate $(95 \% \mathrm{CI})^{\ddagger}$ & & $1.55(1.09-2.22)$ & $1.46(1.03-2.07)$ \\
\hline$p$-value ${ }^{\S}$ & & 0.02 & 0.03 \\
\hline \multicolumn{4}{|l|}{ Lesion activity on brain MRI } \\
\hline T1 gadolinium-enhancing lesions, mean & 0.91 & 0.12 & 0.11 \\
\hline Relative reduction in $\mathrm{T} 1$ gadolinium-enhancing lesions & & $85.7 \%$ & $87.9 \%$ \\
\hline Active $\mathrm{T} 2$ lesions, mean & 1.43 & 0.38 & 0.33 \\
\hline Relative reduction in active $\mathrm{T} 2$ lesions & & $73.4 \%$ & $76.9 \%$ \\
\hline Combined unique lesions, mean & & 0.43 & 0.38 \\
\hline Relative reduction in combined unique lesions & 1.72 & $74.4 \%$ & $77.9 \%$ \\
\hline$p$-value ${ }^{\dagger}$ & & $<0.001$ & $<0.001$ \\
\hline
\end{tabular}

Data are $n(\%)$ unless otherwise indicated

$\mathrm{ARR}=$ annualized relapse rate; $\mathrm{OR}=$ odds ratio $\mathrm{HR}=$ hazard ratio; EDSS = Expanded Disability Status Scale; MRI = magnetic resonance imaging

*Calculated as the ratio of the difference in annualized relapse rate (placebo - cladribine) relative to the ARR in the placebo group

${ }^{\dagger} p$-Value based on Wald $\chi^{2}$ test from analysis of number of relapses using a Poisson regression model with fixed effects for treatment and region, and using log time on study as an offset variable

$\star$ OR and associated $95 \%$ CIs were estimated using a logistic regression model with fixed effects for treatment group and region

${ }^{\S} p$-Value based on Wald $\chi^{2}$ test from analysis of endpoint using a logistic regression model with fixed effects for treatment group and region

Il $p$-Value from Cochran-Mantel-Haenszel row means score differ test, adjusted for baseline number of relapses

"The tenth and fifteenth percentile values are estimated from the Kaplan-Meier survival curve

**The HR, 95\% CIs, and $p$-values were estimated using Cox proportional hazards model with fixed effects for treatment group and region

${ }^{\dagger} p$-Value based on nonparametric ANCOVA model on ranked data with fixed effects for treatment group and region and baseline T1 gadoliniumenhancing lesions as a covariate 
Table 4 Safety overview from the CLARITY study [40]

\begin{tabular}{lllll}
\hline & Placebo & $\begin{array}{l}\text { Cladribine } \\
3.5 \mathrm{mg} / \mathrm{kg}\end{array}$ & $\begin{array}{l}\text { Cladribine } \\
5.25 \mathrm{mg} / \mathrm{kg}\end{array}$ & $\begin{array}{l}\text { Cladribine } \\
\text { overall }\end{array}$ \\
\hline Patients $(n)$ & 435 & 430 & 454 & 884 \\
Any AE & $319(73.3)$ & $347(80.7)$ & $381(83.9)$ & $728(82.4)$ \\
Most common AEs* & & & & \\
$\quad$ Headache & $75(17.2)$ & $104(24.2)$ & $94(20.7)$ & $198(22.4)$ \\
Lymphopenia & $8(1.8)$ & $93(21.6)$ & $143(31.5)$ & $236(26.7)$ \\
Nasopharyngitis & $56(12.9)$ & $62(14.4)$ & $58(12.8)$ & $120(13.6)$ \\
URTI & $42(9.7)$ & $54(12.6)$ & $52(11.5)$ & $106(12.0)$ \\
$\quad$ Nausea & $39(9.0)$ & $43(10.0)$ & $50(11.0)$ & $93(10.5)$ \\
AEs leading to treatment discontinuation & $9(2.1)$ & $15(3.5)$ & $36(7.9)$ & $51(5.8)$ \\
AEs leading to study withdrawal & $5(1.1)$ & $5(1.2)$ & $10(2.2)$ & $15(1.7)$ \\
SAEs & $28(6.4)$ & $36(8.4)$ & $41(9.0)$ & $77(8.7)$ \\
Deaths & $2(0.5)$ & $2(0.5)$ & $2(0.4)$ & $4(0.4)$ \\
Events (n) & 1958 & 2514 & 2712 & 5226 \\
Any AE & $1958(100)$ & $2514(100)$ & $2712(100)$ & $5226(100)$ \\
Most common AEs & & & & \\
$\quad$ Headache & $189(9.7)$ & $264(10.5)$ & $265(9.8)$ & $529(10.1)$ \\
Lymphopenia & $11(0.6)$ & $123(4.9)$ & $195(7.2)$ & $318(6.1)$ \\
Nasopharyngitis & $95(4.9)$ & $107(4.3)$ & $91(3.4)$ & $198(3.8)$ \\
URTI & $80(4.1)$ & $118(4.7)$ & $100(3.7)$ & $218(4.2)$ \\
Nausea & $49(2.5)$ & $74(2.9)$ & $69(2.5)$ & $143(2.7)$ \\
\hline
\end{tabular}

Data are $n(\%)$

$\mathrm{AE}=$ adverse event; $\mathrm{URTI}=$ upper respiratory tract infection; $\mathrm{SAE}=$ serious $\mathrm{AE}$

*Reported by $\geq 10 \%$ of patients in any group months after the end of cladribine treatment. A chest X-ray at this stage showed bilateral alveolar-interstitial infiltrates and a bone marrow biopsy performed 6 days later showed "slight myelodysplasia". At approximately 5 months after the last dose of cladribine tablets, the patient experienced a third episode of pancytopenia. A chest X-ray showed recurrent bilateral alveolar-interstitial lung infiltrates and a repeat bone marrow examination revealed an apparent myelodysplastic syndrome. The patient died from an acute cardiopulmonary arrest approximately 6 months after receiving a single $0.875 \mathrm{mg} / \mathrm{kg}$ treatment course of cladribine. The diagnosis of tuberculosis was obtained postmortem, and the chronic pathological nature of lesions in the liver and lungs, together with the temporal relationship between treatment and acute onset of symptoms, suggested that the tuberculosis was longstanding and present prior to cladribine treatment [40]. Cladribine therapy is likely to have contributed to the worsening of the tuberculosis infection. The myelodysplasia-like condition was probably reactive bone marrow changes caused by the chronic tuberculosis infection and upon review this was determined not to be a case of true myelodysplastic syndrome as there were no cytogenetic abnormalities and its presentation was not consistent with the natural history of myelodysplasia [40].

\section{Pregnancies}

Contraception was specified for women and men of childbearing potential during clinical trials with cladribine tablets; however, pregnancies have occurred. A small number of pregnancies occurred during CLARITY [12], and CLARITY Extension (Cladribine-Placebo $3.5 \mathrm{mg} / \mathrm{kg}, n=1$; PlaceboCladribine $3.5 \mathrm{~kg} / \mathrm{mg}, n=2$ ), but the outcomes were not reported. In ORACLE-MS, 7 pregnancies were reported (placebo, $n=3$; cladribine tablets $3.5 \mathrm{mg} / \mathrm{kg}, n=1$; cladribine tablets $5.25 \mathrm{mg} / \mathrm{kg}, n=3$ ), 5 of which resulted in the birth of healthy infants (1 patient in the placebo group had a spontaneous abortion, and the outcome was unknown in 1 patient treated with cladribine tablets $5.25 \mathrm{mg} / \mathrm{kg}$ ). It was also reported that the partners of 4 male patients in ORACLE-MS became pregnant ( 1 in each active treatment group and 2 in the placebo group). The outcomes of the placebo-group pregnancies were unknown, but the 2 pregnancies in patients treated with cladribine tablets resulted in the birth of healthy infants [44].

\section{Vaccination}

In patients with RRMS receiving continuous immunosuppressive therapy (maintenance therapy), the use of live or 
Table 5 Serious adverse events from the CLARITY study $[12,40]$

\begin{tabular}{|c|c|c|c|c|}
\hline Patients & $\begin{array}{l}\text { Placebo } \\
(n=435)\end{array}$ & $\begin{array}{l}\text { Cladribine } 3.5 \\
\mathrm{mg} / \mathrm{kg} \\
(\mathrm{n}=430)\end{array}$ & $\begin{array}{l}\text { Cladribine } 5.25 \\
\mathrm{mg} / \mathrm{kg} \\
(\mathrm{n}=454)\end{array}$ & $\begin{array}{l}\text { Cladribine } \\
\text { overall } \\
(\mathrm{n}=884)\end{array}$ \\
\hline Any SAE & $28(6.4)$ & $36(8.4)$ & $41(9.0)$ & $77(8.7)$ \\
\hline \multicolumn{5}{|c|}{ Most common SAEs that show treatment differences by system organ class ${ }^{*}, \dagger$} \\
\hline Neoplasms — benign, malignant, and unspecified & 0 & $6(1.4)$ & $4(0.9)$ & $10(1.1)$ \\
\hline GI disorders & $2(0.5)$ & $4(0.9)$ & $5(1.1)$ & $9(1.0)$ \\
\hline Injury, poisoning, and procedural complications & $2(0.5)$ & $9(2.1)$ & 0 & $9(1.0)$ \\
\hline \multicolumn{5}{|c|}{ Most common SAEs that show treatment differences by preferred term ${ }^{*}$} \\
\hline Uterine leiomyoma & 0 & $3(0.7)$ & $2(0.4)$ & $5(0.6)$ \\
\hline Lymphopenia & 0 & $3(0.7)$ & $1(0.1)$ & $4(0.5)$ \\
\hline Events $(n)$ & 1958 & 2514 & 2712 & 5226 \\
\hline Any SAE & $44(2.2)$ & $61(2.4)$ & $80(2.9)$ & $141(2.7)$ \\
\hline \multicolumn{5}{|c|}{ Most common SAEs that show treatment differences by system organ class* ${ }^{*} \uparrow$} \\
\hline Neoplasms — benign, malignant, and unspecified & 0 & $6(0.2)$ & $4(0.1)$ & $10(0.2)$ \\
\hline GI disorders & $4(0.2)$ & $5(0.2)$ & $7(0.3)$ & $12(0.2)$ \\
\hline Injury, poisoning, and procedural complications & $3(0.2)$ & $17(0.7)$ & 0 & $17(0.3)$ \\
\hline \multicolumn{5}{|c|}{ Most common SAEs that show treatment differences by preferred term ${ }^{\dagger, t}$} \\
\hline Uterine leiomyoma & 0 & $3(0.1)$ & $2(0.1)$ & $5(0.1)$ \\
\hline Lymphopenia & 0 & $3(0.1)$ & $1(<0.1)$ & $4(0.1)$ \\
\hline
\end{tabular}

Data are $n(\%)$

$\mathrm{SAE}=$ serious adverse event; $\mathrm{GI}=$ gastrointestinal

* Reported in $>1 \%$ of patients in any treatment group

$\dagger$ The percentage of patients in one active treatment group is $\geq 2 \times$ the percentage of patients in the placebo group, or the percentage of patients in the placebo group is $\geq 2 \times$ the percentage of patients in the active treatment group

${ }^{\star}$ Reported in $>0.5 \%$ of patients in any treatment group

attenuated live vaccines is contraindicated. Cladribine tablets are administered during very short treatment courses and the use of live or attenuated live vaccines should be avoided during treatment, and afterwards for as long as patients' white blood cell counts are not within normal limits.

\section{Follow-On Studies}

To provide long-term safety data all patients who have participated in clinical trials of oral cladribine are eligible for the PREMIERE study (the PRospective observational long-term safEty registry of MS patIEnts who have participated in clinical trials with cladRibinE tablets) [51].

\section{Conclusion}

In an increasingly complex and competitive treatment landscape oral cladribine is likely to be used in patients that are medication-naïve and as switch therapy in patients with suboptimal control of their disease on another DMT or with poor tolerance of their existing DMT. The posology of oral cladribine as a pulsed immune reconstitution therapy (IRT) with effectiveness beyond 2 years of treatment may make in an attractive option to some patients, for example women wanting to start and/or extend their families. Oral cladribine will need to used carefully after other immune-depleting therapies to reduce the risk of long-term lymphopenia. Similarly, the slow reconstitution of lymphocyte subsets after oral cladribine has implications for sequencing of therapies postcladribine. Finally, the availability of relatively cheap generic parenteral cladribine may allow people with MS living in resource-poor environments easier access to an effective DMT albeit it not the licensed oral formulation.

\section{Compliance with Ethical Standards}

Disclosures Professor Giovannoni has received consulting fees for participating on advisory boards in relation to clinical trial design, trial steering committees and data and safety monitoring committees from AbbVie, Almirall, Atara Bio, Bayer Schering Healthcare, Biogen, Five Prime Therapeutics, Genzyme-Sanofi, Merck-Serono, Merck, Novartis, Synthon, Teva, UCB Pharma, and Vertex Pharmaceuticals; lecture fees from AbbVie, Bayer Schering Healthcare, Biogen, Merck Serono, and 
Vertex Pharmaceuticals; and grant support from Bayer Schering Healthcare, Biogen, GW Pharmaceuticals, Ironwood Pharmaceuticals, Merck Serono, Merz, Novartis, and Teva.

\section{References}

1. Carson DA, Wasson DB, Taetle R, Yu A. Specific toxicity of 2chlorodeoxyadenosine toward resting and proliferating human lymphocytes. Blood 62(4), 737-743 (1983).

2. Sipe JC. Cladribine for multiple sclerosis: review and current status. Expert Rev. Neurother. 5(6), 721-727 (2005).

3. Sipe JC, Romine JS, Koziol JA, McMillan R, Zyroff J, Beutler E. Cladribine in treatment of chronic progressive multiple sclerosis. Lancet. 344(8914), 9-13 (1994).

4. Beutler E. Cladribine (2-chlorodeoxyadenosine). Lancet. 340(8825), 952-956 (1992).

5. Rice GP, Filippi M, Comi G. Cladribine and progressive MS: clinical and MRI outcomes of a multicenter controlled trial. Cladribine MRI Study Group. Neurology. 54(5), 1145-1155 (2000).

6. Beutler E, Sipe J, Romine J, McMillan R, Zyroff J, Koziol J. Treatment of multiple sclerosis and other autoimmune diseases with cladribine. Semin. Hematol. 33(1 Suppl. 1), 45-52 (1996).

7. Romine JS, Sipe JC, Koziol JA, Zyroff J, Beutler E. A doubleblind, placebo-controlled, randomized trial of cladribine in relpaasing-remitting multiple sclerosis. Proc. Assoc. Am. Physicians. 111(1), 35-44 (1999).

8. Janiec K, Wajgt A, Kondera-Anasz Z. Effect of immunosuppressive cladribine treatment on serum leucocytes system in two-year clinical trial in patients with chronic progressive multiple sclerosis. Med. Sci. Monit. 7(1), 93-98 (2001).

9. Niezgoda A, Losy J, Mehta PD. Effect of cladribine treatment on beta-2 microglobulin and soluble intercellular adhesion molecule 1 (ICAM-1) in patients with multiple sclerosis. Folia Morphol. . 60(3), 225-228 (2001).

10. Bartosik-Psujek H, Belniak E, Mitosek-Szewczyk K, Dobosz B, Stelmasiak Z. Interleukin-8 and RANTES levels in patients with relapsing-remitting multiple sclerosis (RR-MS) treated with cladribine. Acta Neurol. Scand. 109(6), 390-392 (2004).

11. Kopadze T, Döbert M, Leussink VI, Dehmel T, Kieseier BC. Cladribine impedes in vitro migration of mononuclear cells: a possible implication for treating multiple sclerosis. Eur. J. Neurol. 16(3), 409-412 (2009).

12. Giovannoni G, Comi G, Cook S, et al. A placebo-controlled trial of oral cladribine for relapsing multiple sclerosis. N. Engl. J. Med. 362(5), 416-426 (2010).

13. Kawasaki H, Carrera CJ, Piro LD, Saven A, Kipps TJ, Carson DA. Relationship of deoxycytidine kinase and cytoplasmic 5'-nucleotidase to the chemotherapeutic efficacy of 2-chlorodeoxyadenosine. Blood. 81(3), 597-601 (1993).

14. Wu C, Orozco C, Boyer J, et al. BioGPS: an extensible and customizable portal for querying and organizing gene annotation resources. Genome Biol. 10(11), R130 (2009).

15. Saven A, Foon KA, Piro LD. 2-Chlorodeoxyadenosine-induced complete remissions in Langerhans-cell histiocytosis. Ann. Intern. Med. 121(6), 430-432 (1994).

16. Griffig J, Koob R, Blakley RL. Mechanisms of inhibition of DNA synthesis by 2-chlorodeoxyadenosine in human lymphoblastic cells. Cancer Res. 49(24 Pt 1), 6923-6928 (1989).

17. Laugel B, Challier J, Siegfried C, Chvatchko Y, Salvat C, Weissert $\mathrm{R}$. The mechanism of action behind the lymphocyte-depleting and immunomodulatory effects of cladribine. Abstract P01. 108. In: 61st Annual Meeting of the American Academy of Neurology. (2009).
18. Hentosh P, Peffley DM. The cladribine conundrum: deciphering the drug's mechanism of action. Expert Opin. Drug Metab. Toxicol. 6(1), 75-81 (2010).

19. Korsen M, Alonso SB, Peix L, Bröker BM, Dressel A. Cladribine exposure results in a sustained modulation of the cytokine response in human peripheral blood mononuclear cells. Plos One. 10(6), e0129182 (2015).

20. Juliusson G, Christiansen I, Hansen MM, et al. Oral cladribine as primary therapy for patients with B-cell chronic lymphocytic leukemia. J. Clin. Oncol. 14(7), 2160-2166 (1996).

21. Ogura M, Morishima Y, Kobayashi Y, et al. Durable response but prolonged cytopenia after cladribine treatment in relapsed patients with indolent non-Hodgkin's lymphomas: results of a Japanese phase II study. Int. J. Hematol. 80(3), 267-277 (2004).

22. Schirmer M, Mur E, Pfeiffer KP, Thaler J, Konwalinka G. The safety profile of low-dose cladribine in refractory rheumatoid arthritis. Scand. J. Rheumatol. 26(5), 376-379 (1997).

23. Davis JC, Austin H, Boumpas D, et al. A pilot study of 2-chloro-2'deoxyadenosine in the treatment of systemic lupus erythematosusassociated glomerulonephritis. Arthritis Rheumatol 41(2), 335-343 (1998).

24. Beutler E, Sipe JC, Romine JS, Koziol JA, McMillan R, Zyroff J. The treatment of chronic progressive multiple sclerosis with cladribine. Proc. Natl. Acad. Sci. U. S. A. 93(4), 1716-1720 (1996).

25. Sipe JC. Cladribine tablets: a potential new short-course annual treatment for relapsing multiple sclerosis. Expert Rev. Neurother. 10(3), 365-375 (2010)

26. Lindemalm S, Savic RM, Karlsson MO, Juliusson G, Liliemark J, Albertioni F. Application of population pharmacokinetics to cladribine. BMC Pharmacol. 5, 4 (2005).

27. Liliemark J, Albertioni F, Juliusson G, Eksborg S. A limited sampling strategy for estimation of the cladribine plasma area under the concentration versus time curve after intermittent i.v. infusion, s.c. injection, and oral administration. Cancer Chemother. Pharmacol. 38(6), 536-540 (1996).

28. Liliemark J. The clinical pharmacokinetics of cladribine. Clin. Pharmacokinet. 32(2), 120-131 (1997).

29. Guarnaccia JB, Rinder H, Smith B. Preferential effects of cladribine on lymphocyte subpopulations. Mult. Scler. 14, S45-sS45 (2008).

30. Soelberg-Sorensen P, Comi G, Cook S, et al. Effects of cladribine tablets on haematological profiles in patients with relapsingremitting multiple sclerosis (RRMS) in the 96 week, phase III, double-blind, placebo-controlled CLARITY study. Meeting Abstract. In: Annual Congress of European Committee for Treatment and Research in Multiple Sclerosis (ECTRIMS), Dusseldorf, Germany. 9-12 (2009).

31. Saven A, Piro LD. 2-Chlorodeoxyadenosine in the treatment of hairy cell leukemia. Cancer Invest. 11(5), 559-564 (1993).

32. Leist TP, Vermersch P. The potential role for cladribine in the treatment of multiple sclerosis: clinical experience and development of an oral tablet formulation. Curr. Med. Res. Opin. 23(11), 26672676 (2007).

33. McDonald WI, Compston A, Edan G, et al. Recommended diagnostic criteria for multiple sclerosis: guidelines from the International Panel on the diagnosis of multiple sclerosis. Ann. Neurol. 50(1), 121-127 (2001).

34. Fazekas F, Barkhof F, Filippi M, et al. The contribution of magnetic resonance imaging to the diagnosis of multiple sclerosis. Neurology. 53(3), 448-456 (1999).

35. Rammohan K, Giovannoni G, Comi G, et al. Cladribine tablets for relapsing-remitting multiple sclerosis: Efficacy across patient subgroups from the phase III CLARITY study. Mult. Scler. Relat. Disord. 1(1), 49-54 (2012).

36. Comi G, Cook S, Giovannoni G, et al. FP36-WE-03 MRI outcomes of short-course oral treatment with cladribine tablets for relapsingremitting multiple sclerosis (RRMS) in the 96-week, phase III, 
double-blind, placebo-controlled CLARITY study. J. Neurol. Sci. 285, S114 (2009).

37. Comi G, Cook SD, Giovannoni G, et al. MRI outcomes with cladribine tablets for multiple sclerosis in the CLARITY study. J. Neurol. 260(4), 1136-1146 (2013).

38. Giovannoni G, Cook S, Rammohan K, et al. Sustained diseaseactivity-free status in patients with relapsing-remitting multiple sclerosis treated with cladribine tablets in the CLARITY study: a post-hoc and subgroup analysis. Lancet Neurol. 10(4), 329-337 (2011).

39. De Stefano N, Giorgio A, Battaglini M, De Leucio A, Hicking C, Dangond F, Giovannoni G, Sormani MP. Reduced brain atrophy rates are associated with lower risk of disability progression in patients with relapsing multiple sclerosis treated with cladribine tablets. Mult. Scler. 1352458517690269 (2017). https://doi.org/10. $1177 / 1352458517690269$.

40. Cook S, Vermersch P, Comi G, et al. Safety and tolerability of cladribine tablets in multiple sclerosis: the CLARITY (CLAdRIbine Tablets treating multiple sclerosis orallY) study. Mult. Scler. 17(5), 578-593 (2011).

41. Ali S, Paracha N, Cook S, et al. Reduction in healthcare and societal resource utilization associated with cladribine tablets in patients with relapsing-remitting multiple sclerosis: analysis of economic data from the CLARITY Study. Clin. Drug Investig. 32(1), 15-27 (2012).

42. Giovannoni G, Soelberg Sorensen P, Cook S, Rammohan K, Rieckmann P, Comi G, Dangond F, Adeniji AK, Vermersch P. Safety and efficacy of cladribine tablets in patients with relapsingremitting multiple sclerosis: Results from the randomized extension trial of the CLARITY study. Mult. Scler. 1352458517727603 (2017). https://doi.org/10.1177/1352458517727603.

43. Soelberg-Sorensen P, Dangond F, Hicking C, Giovannoni G. Absolute lymphocyte count recovery in patients with relapsingremitting multiple sclerosis (RRMS) treated with cladribine tablets
$3.5 \mathrm{mg} / \mathrm{kg}$ in CLARITY and CLARITY Extension (P5.379). Neurology 88(16 Suppl.) (2017).

44. Leist TP, Comi G, Cree BAC, et al. Effect of oral cladribine on time to conversion to clinically definite multiple sclerosis in patients with a first demyelinating event (ORACLE MS): a phase 3 randomised trial. Lancet Neurol. 13(3), 257-267 (2014).

45. Giovannoni G, Comi G, Cook S, et al. Safety and efficacy of oral cladribine in patients with relapsing-remitting multiple sclerosis: results from the 96 week phase IIIb extension trial to the CLARITY study (P07.119). Neurology 80(7 Suppl.), P07.119P07.119 (2013).

46. Cook S, Vermersch P, Comi G, et al. PO10-TU-39 Safety and tolerability of short-course oral treatment with cladribine tablets for relapsing-remitting multiple sclerosis (RRMS) in the 96-week, phase III, double-blind, placebo-controlled CLARITY study. J. Neurol. Sci. 285, S206 (2009).

47. Giovannoni G, Sorensen PS, Butzkueven H, et al. Mitigating severe lymphopenia: post hoc analysis of data from the 96-week CLARITY study. Mult. Scler. 17, S454-S455 (2011).

48. Baker D, Herrod SS, Alvarez-Gonzalez C, Zalewski L, Albor C, Schmierer K. Both cladribine and alemtuzumab may effect MS via B-cell depletion. Neurology Neuroimmunol Neuroinflamm 4(4), e360 (2017).

49. Pakpoor J, Disanto G, Altmann DR, et al. No evidence for higher risk of cancer in patients with multiple sclerosis taking cladribine. Neurol Neuroimmunol Neuroinflamm 2(6), e158 (2015).

50. Cheson BD, Vena DA, Barrett J, Freidlin B. Second malignancies as a consequence of nucleoside analog therapy for chronic lymphoid leukemias. J. Clin. Oncol. 17(8), 2454-2460 (1999).

51. Miret M, Weiner J, Gedney L, Greenberg S, Alteri E. Evaluation of the long-term safety of cladribine tablets in multiple sclerosis: design of PREMIERE, a prospective, observational 8-year safety registry. J. Neurol. 257, S144 (2010). 